\title{
Os desafios do atual contexto: um diálogo a partir da seguridade
}

\section{The current context's challenges: a dialogue starting from the Social Security}

\author{
Mariangela Belfiore Wanderley ${ }^{a}$ \\ (1) https://orcid.org/0000-0003-3894-6478 \\ Raquel Santos Sant'Ana \\ (1) https://orcid.org/0000-0002-2270-5541 \\ Maria Lúcia Martinellic \\ (D) https://orcid.org/0000-0001-9124-2846
}

O momento que vivemos é pleno de desafios. Mais do que nunca é preciso ter coragem, é preciso ter esperanças e enfrentar o tempo presente.

Marilda Iamamoto

ste número da Revista Serviço Social \& Sociedade tem como foco
central o tema da Previdência Social, questão em debate e disputa
na sociedade, a partir de diferentes projetos políticos. De um lado, temos o atual governo que justifica o Projeto da Reforma da Previdência Social, entregue ao Congresso Nacional, sob a égide de sua sustentabilidade e equilíbrio fiscal, com promessas de um crescimento vigoroso baseado nas expectativas dos mercados. De outro lado, segmentos da sociedade civil questionam a anacrônica Reforma, alertando que um direito social fundamental do brasileiro está em perigo e representa um grande retrocesso face a um conjunto de direitos constante na Constituição de 1988, marco civilizatório de suma importância! 
Estudiosos têm se debruçado sobre a Proposta de Reforma do Governo Bolsonaro, produzindo fecundas análises. Um deles, por exemplo, Guilherme Santos Mello, professor do Instituto de Economia da Unicamp e pesquisador do Centro de Estudos de Conjuntura e Política Econômica (CECON-Unicamp), em artigo publicado no site Brasil Debate em 22/2/2019, aponta que não há dúvidas de que o sistema de previdência social se tornará ainda mais excludente, pelo seu "esfacelamento gradual, enquanto regimes de capitalização públicos e privados se fortalecerão". Trata-se, pois, de "demolir as bases do atual sistema de seguridade social, substituindo-o por um sistema de capitalização privado. Na prática, isso significa a mudança do princípio da solidariedade social pela lógica individual".

Eduardo Fagnani, professor do Instituto de Economia da Unicamp, tem sido um crítico ferrenho da Reforma da Previdência pretendida pela equipe econômica do presidente Bolsonaro. A seu juízo, o sistema se tornará ainda mais excludente, uma vez que um contingente maior de trabalhadores não conseguirá cumprir os requisitos mínimos para requerer a aposentadoria. Enfatiza que, em meio à precarização, ela desmontará a Seguridade, liquidará a ideia de que a aposentadoria é um direito e obrigará os poucos privilegiados a recorrerem a planos privados (site Outras mídias, 26/2/2019). Efetivamente está em curso um novo modelo de sociedade que sepulta o pacto de 1988 .

Estes pesquisadores, dentre tantos outros, apontam os perigos do desmonte da seguridade social para os trabalhadores e, por que não dizer, para a sociedade brasileira, que se tornará ainda mais desigual com consequências danosas para todos.

Os artigos que tratam da temática evidenciam o quanto são sombrios os tempos que vivemos e como estamos todos, população usuária, trabalhadores e instituições, afrontados pelos ataques cotidianos aos direitos sociais duramente conquistados há tantos anos.

É bem oportuna, nesse sentido, a lembrança do poeta Carlos Drummond de Andrade, evocada por Marilda Iamamoto, em seu livro O Serviço Social na contemporaneidade (1998, p. 17), dizendo-nos que "este é um tempo de divisas, tempo de gente cortada".

Talvez nem o leitor, nem nós mesmos, pudéssemos supor que, passados mais de vinte anos dessa publicação, estaríamos imersos numa crise sem precedentes, de graves afrontas ao campo dos direitos. 
O ano de 2019 marca a chegada ao poder, pelo voto direto, de um presidente ultraconservador, que traz no seu plano de governo uma proposta econômica radicalmente liberal.

Do ponto de vista político, a ordem democrática está em risco, pois várias investidas têm sido feitas sobre a liberdade de expressão e pensamento.

$\mathrm{O}$ ataque à diversidade humana, às conquistas das mulheres, à liberdade de imprensa, e tantas outras violências perpetradas, de modo velado ou explícito, são apresentadas como soluções para atuar junto às tensões oriundas dos conflitos de classes e da extrema desigualdade vivenciada no Brasil.

Neste contexto bastante adverso à afirmação dos direitos humanos e sociais, a Revista Serviço Social \& Sociedade conclama seu compromisso com ideais libertários e com a defesa intransigente dos direitos de cidadania.

O artigo que abre este número, de autoria de Mauri Antônio Silva, apresenta uma rigorosa análise crítica da Reforma da Previdência Social no Brasil, entre os anos 2016 e 2018. O autor faz uma análise pormenorizada da Contrarreforma da Previdência proposta pelo governo por meio da Emenda Constitucional n. 287/2016 e mostra seus trâmites e alterações até o presente momento. Os direitos dos trabalhadores, resultado de décadas de lutas e embates, estão sendo violentamente atacados. Aliás, todos os direitos são conquistas, emanados da organização da classe trabalhadora. Desde a revolução industrial na Europa, passando pelas particularidades da formação da sociedade brasileira, até as lutas atuais, os direitos foram sendo arduamente conquistados, deixando para traz, inclusive, um grande número de mortos, seja devido às péssimas condições de trabalho, seja em função da luta e resistência dos trabalhadores. Nos últimos dois anos, a ênfase governamental numa proposta radicalmente neoliberal tem afetado os trabalhadores do ponto de vista econômico, mas principalmente do ponto de vista dos direitos do trabalho.

O Serviço Social brasileiro há muito enfatiza este debate sobre o Estado e as políticas públicas, devido a sua própria inserção na divisão sociotécnica do trabalho, afinal enfrentar esta problemática é uma condição fundamental para evitar qualquer "ilusão social democrata”.

As dificuldades de acesso ao Benefício de Prestação Continuada (BPC), previsto na Lei Orgânica da Assistência Social (LOAS), são analisadas por Roberta Stopa. Ainda que seja um benefício importante para assegurar o 
acesso aos direitos de cidadania de uma parcela da população, os critérios e trâmites burocráticos fazem com que nem sempre este acesso seja possível por parte daquele que requer e necessita do benefício.

Aliás, o BPC está, também, na mira da Reforma da Previdência Social entregue pelo governo ao Congresso, propondo o pagamento de um valor menor que o salário mínimo, de $\mathrm{R} \$ 400$, a partir dos 60 anos de idade. Caso o idoso não tenha o tempo mínimo de contribuição para se aposentar pelo regime geral ao atingir 65 anos, ele continuará recebendo aquele mesmo valor até completar 70 anos. São atingidos, assim, os cidadãos mais vulneráveis de nossa sociedade, idosos que não têm como se sustentar.

Ainda no espectro da Previdência Social, o artigo de autoria de Alano do Carmo Macêdo e Thaynah Barros de Araújo discute a aposentadoria do trabalhador com deficiência que é segurado do Regime Geral da Previdência Social, e mostra as dificuldades de acesso oriundas de um sistema previdenciário típico de um país periférico e dependente, o que leva a constantes violações dos direitos dos trabalhadores.

Completando as reflexões no âmbito da Seguridade Social, o artigo de Tânia Regina Krüger e Camila Reis traz os resultados de pesquisa sobre a presença das Organizações Sociais nos Planos Estaduais de Saúde e a constatação de que, ainda que esta menção não seja frequente, na realidade, tem sido uma prática recorrente. Quais as intencionalidades que levam a estas parcerias? Privatização de um patrimônio público como o SUS? Na realidade, este é um debate que está em curso e que precisa ser constantemente retomado, pois o processo de privatização dos serviços de saúde tem utilizado estratégias as mais diversas. Conhecer seus mecanismos nos instrumentaliza para a defesa de um sistema de saúde público e universal, conforme previsto na Constituição Brasileira e na Lei Orgânica da Saúde.

A atual conjuntura política tem colocado muitas incertezas à democracia e aos direitos sociais, especialmente aos direitos dos trabalhadores. Daí a necessidade de uma reflexão permanente sobre o atual quadro político, econômico e social e a necessidade de discutir o significado das políticas públicas e seu papel na reprodução da sociabilidade. As autoras Vitória Gehlen e Helena Chaves são responsáveis, nesta edição, por esta interlocução no artigo "Estado, políticas sociais e direitos sociais: descompasso do tempo atual". 
Ampliando o foco, contamos, também, com o artigo de Claudio Horst e Emilly Tenorio que discute a inserção da/o assistente social na atividade de conciliação de conflitos/mediação familiar proposta pelo judiciário brasileiro. $\mathrm{Na}$ realidade, o trabalho mostra as incongruências e impossibilidades de atender o que é demandado ao mediador face ao projeto profissional do serviço social e sua diretriz crítica. Um tema atual e necessário de ser discutido, afinal compõe o debate sobre os fundamentos do trabalho profissional e os desafios presentes na realidade atual.

Participantes de um grupo de assistentes sociais gaúchas, as autoras Graziela Scheffer, Thaisa Closs e Inez Zacarias analisam, com muita propriedade, a renovação do Serviço Social no Rio Grande do Sul, tratando da "Reconceituação latino-americana na Ditadura Brasileira”.

Um interessante artigo sobre os "Movimentos Sociais no Brasil contemporâneo", de autoria de Ana Targina Ferraz, analisa esses importantes sujeitos políticos a partir da crise iniciada em 2008 e de suas expressões políticas mais visíveis: a organização e mobilização social em redes, fóruns e coletivos. Destaca, também, a importância das mídias sociais e das tecnologias informacionais que têm dado maior capilaridade e capacidade de articulação entre esses espaços coletivos.

Fechamos o conjunto de artigos com uma valiosa reflexão sobre as contribuições de Celso Furtado, “o cavaleiro errante de destemido coração", nas palavras dos autores Rogério Faleiros, Ednilson Felipe e Daniel Sampaio. Crítico da realidade brasileira, Furtado deixou importante legado teórico para se pensar e repensar o Brasil.

Duas interessantes resenhas completam este número. Uma delas trata da obra intitulada Tempos Modernos, Jornadas Antigas, de Pietro Basso, contendo uma relevante análise sobre vidas de trabalho no início do século XXI.

A outra tem por tema a Economia Solidária, destacando a importância do pensamento de Paul Singer, oportunidade na qual rendemos nossas homenagens por seu relevante legado ao pensamento crítico brasileiro.

Vale ressaltar que, nesta edição da Revista, a reflexão sobre o trabalho profissional do Assistente Social perpassa direta ou indiretamente grande parte dos artigos. 
A atual conjuntura política tem colocado muitas incertezas à democracia e aos direitos sociais, especialmente aos direitos dos trabalhadores. Daí a necessidade de uma reflexão permanente sobre o atual quadro político, econômico e social, bem como sobre o significado das políticas públicas e seu papel na reprodução da sociabilidade contemporânea.

Os artigos que integram o presente número trazem importantes contribuições, constituindo-se em leitura indispensável para todos aqueles que se colocam na luta intransigente por direitos.

\section{Referências}

ANDRADE, Carlos Drummond. Nosso tempo. Poesia e Prosa. Rio de Janeiro: Nova Aguilar, 1983. p. 166.

FAGNANI, Eduardo. Previdência: Fagnani disseca a proposta Bolsonaro. Outras mídias, 26 fev. 2019. Entrevista concedida ao IHU On-Line (Instituto Humanitas Unisinos). Disponível em: https://outraspalavras.net/outrasmidias/previdencia-fagnani-disseca-a-proposta-bolsonaro/. Acesso em: 10 abr. 2019.

IAMAMOTO, Marilda Villela. O Serviço Social na contemporaneidade: trabalho e formação profissional. São Paulo: Cortez, 2015.

MELLO, Guilherme Santos. A cruel demolição da previdência social. Brasil Debate, 22 fev. 2019. Disponível em: http://brasildebate.com.br/a-cruel-demolicao-da-previdencia-social/. Acesso em: 10 abr. 2019.

\section{Sobre as autoras}

Mariangela Belfiore Wanderley - Assistente Social. Professora associada do Departamento de Política e Gestão. Docente do Programa de Pós-Graduação em Serviço Social.

E-mail: mariangela.belfiore@gmail.com

Raquel Santos Sant'Ana - Assistente social. Doutora em Serviço Social. E-mail: raquelssfranca@yahoo.com.br

Maria Lúcia Martinelli - Assistente social. Doutora em Serviço Social. E-mail:mlmartinelli@terra.com.br 